\title{
The paediatric global musculoskeletal task force - 'towards better MSK health for all'
}

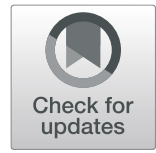

\author{
Helen E. Foster ${ }^{1 *}$ D, Christiaan Scott ${ }^{2}$, Carl J. Tiderius ${ }^{3}$ and Matthew B. Dobbs ${ }^{4}$
}

\begin{abstract}
There is increasing concern about the emerging global non-communicable diseases (NCDs) burden. The focus has mainly been on NCDs in adults but it is important that MSK morbidity in both children and adults is included in strategic planning. There have been considerable advances in the understanding and treatment options for children and young people (CYP) and clinical outcomes are improving for those who can access such high quality care. However vast inequity exists and there are many CYP who live in areas of the world with high burden of health care challenges, compounded by paucity of specialist care and limited access to treatments. The Paediatric Global Musculoskeletal Task Force aims to raise awareness about unmet needs for CYP with MSK conditions, promotion of MSK health through lifestyle and the avoidance of injury. We aim to leverage change through 'working together better'.
\end{abstract}

Keywords: Musculoskeletal, Global, Access to care, Awareness, Workforce

\section{Background}

There is increasing concern about the emerging global burden of non-communicable diseases (NCDs) and the contributory impact of musculoskeletal (MSK) morbidity on NCDs such as dementia and cardiovascular disease [1-3]. MSK health is often under prioritised in health care systems geared towards the burden of communicable diseases or NCDs in adults [2]. There is also the burgeoning tide of obesity as a harbinger of ill health, including MSK morbidity across the life course, and the impact of chronic pain which often has origins in childhood. The ongoing COVID-19 global pandemic has exposed fault lines in health systems all over the world and also brought into sharp focus global inequalities in the delivery of health care.

The needs of children and young people (CYP) and especially for those with MSK problems, are often overlooked - more so in countries with limited resources and

\footnotetext{
* Correspondence: h.e.foster@newcastle.edu.my

${ }^{1}$ Newcastle University, UK and Newcastle University Medicine Malaysia, Newcastle upon Tyne, UK

Full list of author information is available at the end of the article
}

paucity of specialists [4, 5]. Globally, there are many CYP (likely millions) with MSK conditions; the majority living in the poorest and most populous countries in Asia, Africa and South America [5, 6]. Delay in access to 'right care' is well reported [7] and increasingly important given advances in treatment options; the disparity is stark with worse clinical outcomes reported in countries with limited resources $[8,9]$. The paucity of workforce capacity in the most populated and least resourced countries [10] further adds to the challenges and many CYP are unlikely to receive equivalent care to those living in well-resourced countries $[11,12]$.

The Paediatric Task Force for Global Musculoskeletal Health ('Task Force') is a virtual global community with a shared vision to 'work better together' to improve the lives of CYP. Our focus is 'MSK' in the broadest sense and optimising MSK health through lifestyle, avoidance of injury (including road safety) and reducing obesity. The Task Force was set up in 2017 as part of the Global Alliance for Musculoskeletal Health (G-MUSC) https:// gmusc.com, with one of us (HF) as chair and invited cochairs joining in 2019; CS (paediatric rheumatology), 
MD (paediatric orthopaedics) and CT (MSK health promotion). 'Joining forces' with PReS has facilitated momentum and growth with global regional representatives and currently $>280$ members are signed up to group emails (including doctors, nurses, allied health and representatives from professional societies, industry and research consortia). Communications are facilitated through e-Newsletters, social media and 'face to face' meetings at professional gatherings. Our work has no dedicated funding and we acknowledge administrative support from G-MUSC.

\section{Table - Aims of the Task Force}

To Raise Awareness

- About the many children and young people around the world with MSK problems

- About the considerable long-term impact of untreated MSK conditions starting in early life: impact on young people, their families, carers and society

- That many conditions are treatable; long term disability can be avoided thus reducing 'cost' to individuals and society

To Identify and Promote tangible exemplar solutions to improve access to 'right' care

- Models of clinical care and access to medicines

- Education and training 'fit for purpose' and to increase workforce capacity

- Promote contextually relevant research and wider inclusion

To Promote healthy joints and bones

- Through lifestyle (e.g. diet, exercise, behaviours)

- Reduce the risk of injury and reduce levels of obesity

- Reduce the long term risk of osteoarthritis and osteoporosis

Our 'modus operandi' is 'working better together', with focus on learning from each other. It is imperative that we do not 'reinvent the wheel'; our efforts have been to engage widely, identify exemplar solutions and foster collaborations to extend their benefit to more individuals across different health care contexts. We focus on 'low hanging fruit'; identifying and supporting exemplars with greatest potential impact and at lower 'cost' in terms of resource. Our 'Call to Action' encompasses awareness, workforce capacity, models of care, research and policy themes to address the spectrum of MSK health [13]. In many of the exemplar initiatives listed below, Task Force members are working in collaboration to increase their reach and impact.

Awareness, advocacy and policy:

- WOrld young Rheumatic Diseases day (WORD) (https://wordday.org); An awareness initiative with global participation and to promote the importance of early diagnosis and access to specialist care.

- The Paediatric Bone and Joint Day (https://www. usbji.org/programs/pediatric-specialty-group/world- pediatric-bone-and-joint-day) highlighting lifestyle changes to optimise MSK health.

- Generation Pep: A programme to encourage physical activity and healthy lifestyle behaviours (https://generationpep.se/sv/).

- Promotion of MSK disability as an important contribution to global NCD burden (e.g. http:// www.ncdchild.org)

- The WHO Essential Medicines List (https://list. essentialmeds.org/). An effort is in progress to increase the medications available for paediatric rheumatic diseases [14].

- Juvenile Arthritis Management in Less resourced Countries [15] highlighted need for pragmatic clinical guidelines and research to inform clinical practice in LRIC and a further needs assessment for South East Asia and Asia Pacific countries is underway.

- Wikipedia as an open e-resource with reach to a wide audience. An effort is underway to update relevant pages (e.g https://en.wikipedia.org/wiki/ Juvenile_idiopathic_arthritis).

\section{Models of care, education and training:}

- MiracleFeet: A global programme to develops and support local teams to facilitate diagnosis and management of clubfoot (https://www.miraclefeet.org).

- Project ECHO: A global multidisciplinary educational platform for health care professionals (https://echo.unm.edu/) to enable delivery of high quality clinical care within clinical networks [16].

- RightPath (http://www.rightpath.solutions) is a community-based MSK triage model delivered by paediatric physiotherapists.

- Paediatric Musculoskeletal Matters (PMM) [17] (http://www.pmmonline.org) as a free e-resource with content from global partners, global initiatives for MSK curricula [18, 19] and rheumatology training programmes in countries where specialist care is lacking [19].

- PReS training schemes (e.g. https://www.pres.eu/ activities/young-investigators/fellowship-programs. html) open to countries outside of Europe and bursaries for clinicians from LRIC to existing CME events (e.g. EULAR and PReS meetings).

\section{Conclusions}

\section{"If you want to go fast, go alone. If you want to go far, go together" - African proverb}

The Task Force has gained considerable momentum through amazing engagement and motivation within our 
global community. More needs to be done and can be done through working better together. Greater awareness and collaboration can enable us to harness existing and emerging knowledge, innovations and technical advances to make real impact and achieve 'better MSK health for all'. Moving forwards, our 'Call to Action' will inform a roadmap to enable real change.

Paediatric Global MSK Task Force: https://gmusc. com/musculoskeletal-problems-in-children-and-youngpeople/

Twitter@paedmskglobal.

\section{Abbreviations}

CYP: Children and Young People; EML: Essentials Medicine List; EULAR: European League Against Rheumatism; G-MUSC: Global Alliance for Musculoskeletal Health; LRIC: Low Resource Income Countries; PMM: Paediatric Musculoskeletal Matters; PReS: Pediatric Rheumatology European Society; MRIC: Middle Resource Income Countries; MSK: Musculoskeletal; NCD: Non-Communicable Diseases; WHO: World Health Organisation

\section{Authors' contributions}

All authors approved the final manuscript as submitted and agree to be accountable for all aspects of the work. HF wrote the manuscript and CS, CT and MD reviewed and revised the manuscript.

\section{Funding}

This work had no specific funding support.

\section{Availability of data and materials}

There is no data generated to analyse.

\section{Ethics approval and consent to participate}

Ethical approval was not deemed appropriate for this study. Consent from patients is not applicable in this study.

\section{Consent for publication}

All authors give consent for publication.

\section{Competing interests}

The authors declare that they have no competing interests. The authors have no financial relationships relevant to this article to disclose.

\section{Author details}

${ }^{1}$ Newcastle University, UK and Newcastle University Medicine Malaysia, Newcastle upon Tyne, UK. ${ }^{2}$ University of Cape Town, Cape Town, South Africa. ${ }^{3}$ Skane University Hospital, Lund, Sweden. ${ }^{4}$ Washington University School of Medicine, St Louis, USA.

Received: 9 March 2020 Accepted: 3 July 2020

Published online: 14 July 2020

\section{References}

1. Sebbag E, Felten R, Sagez F, Sibilia J, Devilliers H, Arnaud L. The world-wide burden of musculoskeletal diseases: a systematic analysis of the World Health Organization burden of diseases database. Ann Rheum Dis. 2019; 78(6):844-8.

2. Briggs AM, Woolf AD, Dreinhöfer K, Homb N, Hoy DG, Kopansky-Giles D, et al. Reducing the global burden of musculoskeletal conditions. Bull World Health Organ. 2018;96(5):366

3. James SL, Abate D, Abate KH, Abay SM, Abbafati C, Abbasi N, et al. Global, regional, and national incidence, prevalence, and years lived with disability for 354 diseases and injuries for 195 countries and territories, 1990-2017: a systematic analysis for the global burden of disease study 2017. Lancet. 2018;392(10159):1789-858.

4. Henrickson M. Policy challenges for the pediatric rheumatology workforce: Part II. Health care system delivery and workforce supply. Pediatric Rheumatology. 2011;9(1):24.
5. Henrickson M. Policy challenges for the pediatric rheumatology workforce: Part III. the international situation. Pediatric Rheumatology. 2011:9(1):26.

6. Dave M, Rankin J, Pearce M, Foster HE. Global estimates of Clubfoot, Juvenile Idiopathic Arthiritis and Juvenile Systemic Lupus Erythematosus. Pediatric Rheumatology. 2020;18:49. https://doi.org/10.1186/s12969-02000443-8.

7. Foster HE, Rapley T. Access to pediatric rheumatology care -- a major challenge to improving outcome in juvenile idiopathic arthritis. J Rheumatol. 2010:37(11):2199-202.

8. Consolaro A, Giancane G, Alongi A, van Dijkhuizen EHP, Aggarwal A, AlMayouf SM, et al. Phenotypic variability and disparities in treatment and outcomes of childhood arthritis throughout the world: an observational cohort study. The Lancet Child \& Adolescent Health. 2019;3(4):255-63.

9. Dobbs MB, Gurnett CA. Update on clubfoot: etiology and treatment. Clin Orthop Relat Res. 2009:467(5):1146.

10. Harper BD, Waceke Nganga RA, Forsyth KD, Ham HP, Keenan WJ, Russ CM Where are the paediatricians? An international survey to understand the global paediatric workforce. BMJ paediatrics open. 2019;3(1).

11. Scott C. Webb K. Paediatric rheumatology in sub-Saharan Africa: Rheumatology. 2014;53(8):1357-8.

12. Sawhney S, Manners $P$. The place of pediatric rheumatology in India. The Indian Journal of Pediatrics. 2010;77(9):993-6.

13. Foster HE, Scott C, Tiderius CJ, Dobbs MB and members of the Paediatric Global MSK Task Force. Improving Musculoskeletal Health for Children and Young People - a 'call to action'. Best Practice \& Research Clinical Rheumatology. 2020 (in press).

14. Foster HE, Scott C. Update the WHO EML to improve global paediatric rheumatology. Nature Reviews Rheumatology. 2020:1-

15. Scott C, Chan M, Slamang W, Okong'o L, Petty R, Laxer RM, et al. Juvenile arthritis management in less resourced countries (JAMLess): consensus recommendations from the cradle of humankind. Clin Rheumatol. 2019; 38(2):563-75.

16. Arora S, Thornton K, Murata G, Deming P, Kalishman S, Dion D, et al. Outcomes of treatment for hepatitis $C$ virus infection by primary care providers. N Engl J Med. 2011:364(23):2199-207.

17. Smith N, Rapley T, Jandial S, English C, Davies B, Wyllie R, et al. Paediatric musculoskeletal matters (pmm)--collaborative development of an online evidence based interactive learning tool and information resource for education in paediatric musculoskeletal medicine. Pediatric Rheumatology. 2016;14(1):1

18. Al Maini M, Al Weshahi Y, Foster HE, Chehade MJ, Gabriel SE, Al Saleh J, et al. A global perspective on the challenges and opportunities in learning about rheumatic and musculoskeletal diseases in undergraduate medical education. Clin Rheumatol. 2019:1-16.

19. Lewandowski LB, Schiffenbauer A, Mican JM, Moses SJ, Fallah MP, Plotz P, et al. Rheumatology capacity building: implementing a rheumatology curriculum for Liberian health-care providers in. Clin Rheumatol. 2016;2020: $1-8$

\section{Publisher's Note}

Springer Nature remains neutral with regard to jurisdictional claims in published maps and institutional affiliations.

Ready to submit your research? Choose BMC and benefit from:

- fast, convenient online submission

- thorough peer review by experienced researchers in your field

- rapid publication on acceptance

- support for research data, including large and complex data types

- gold Open Access which fosters wider collaboration and increased citations

- maximum visibility for your research: over $100 \mathrm{M}$ website views per year

At BMC, research is always in progress.

Learn more biomedcentral.com/submission 